\title{
Magma chamber detected beneath an arc volcano with high-resolution velocity images
}

\author{
K. Chrapkiewicz ${ }^{1 *}$, M. Paulatto ${ }^{1}$, \\ B. A. Heath ${ }^{2 \dagger}$, E. E. E. Hooft ${ }^{2}$, P. Nomikou ${ }^{3}$, \\ C. B. Papazachos ${ }^{4}$, F. Schmid ${ }^{5}$, D. \\ D. R. Toomey ${ }^{2}, \mathrm{M}$ \\ M. R. Warner ${ }^{1}$, and J. V. Morgan ${ }^{1}$ \\ ${ }^{1}$ Department of Earth Science and Engineering, Imperial College London, United Kingdom \\ ${ }^{2}$ Department of Earth Sciences, University of Oregon, Eugene, United States of America \\ ${ }^{3}$ Department of Geology and Geo-Environment, National and Kapodistrian University of Athens, \\ Greece \\ ${ }^{4}$ Geophysical Laboratory, Aristotle University of Thessaloniki, Greece \\ ${ }^{5}$ GEOMAR Helmholtz-Centre for Ocean Research, Kiel, Germany \\ ${ }^{*}$ Corresponding author (k.chrapkiewicz17@imperial.ac.uk) \\ †Now at National Tsunami Warning Center, Palmer, Alaska, United States of America
}

\begin{abstract}
Arc volcanoes are underlain by complex systems of molten-rock reservoirs ranging from melt-poor mush zones to melt-rich magma chambers. Petrological and satellite data indicate that eruptible magma chambers form in the topmost few kilometres of the crust. However, very few chambers have ever been definitively located, suggesting that most are too short-lived or too small to be imaged, which has direct implications for hazard assessment and modelling of magma differentiation. Here we use a highresolution technology based on inverting full seismic waveforms to image a small, high-melt-fraction magma chamber that was not detected with standard seismic tomography. The melt reservoir extends from $\sim 2$ to at least $4 \mathrm{~km}$ below sea level (b.s.l.) at Kolumbo - a submarine volcano near Santorini, Greece. The chamber coincides with the termination point of the recent earthquake swarms and may be a missing link between a deeper melt reservoir and the high-temperature hydrothermal system venting at the crater floor. The chamber poses a serious hazard as it could produce a highly explosive, tsunamigenic eruption in the near future. Our results suggest that similar reservoirs (relatively small but high melt-fraction) may have gone undetected at other active volcanoes, challenging the existing eruption forecasts and reactive-flow models of magma differentiation.
\end{abstract}

Key words: magma reservoir $\cdot$ Hellenic Arc $\cdot$ Kolumbo volcano $\cdot$ seismic full-waveform inversion 


\section{Main}

Arc volcanoes are the surface expression of magmatic processes that originate from the partial melting of the mantle above subducting plates (England and Katz, 2010). The thermodynamic conditions encountered by the melt as it moves towards the surface govern the volcanic eruption style (Cashman et al., 2017). Highly explosive eruptions of evolved, volatile-rich, viscous magmas at volcanic arcs (Bachmann and Bergantz, 2009) account for $~ 95 \%$ of human fatalities associated with eruptive phenomena (Brown et al., 2017). The explosivity is enhanced at (semi-)submerged volcanoes due to magma-water interactions (Peckover et al., 1973; Wohletz \& Heiken, 1992). Such events can lead to high and voluminous ash clouds, tsunami, and extensive pumice rafts, as occurred in the 1600 BC Santorini (Bond and Sparks, 1976), 1650 AD Kolumbo (Cantner et al., 2014; Fuller et al., 2018), and the recent Tonga (Kusky, 2022) eruptions.

The plumbing systems of arc volcanoes comprise a vertically extensive network of melt reservoirs (Cashman et al., 2017). A step change from melt-controlled to crystal-controlled rheology naturally divides these reservoirs into (melt-rich) magma chambers and (melt-poor) mush zones (Sparks et al., 2019). It is widely accepted that magma differentiation occurs primarily in the deep crust (Annen et al., 2006), while shallow melt storage conditions control the style and volume of eruptions (Cashman et al., 2013; Popa et al., 2021). The question of whether a shallow reservoir is a magma chamber or a mush zone is critical for assessing eruption likelihood and dynamics. Presence of mobile melt (magma) allows for a rapid eruption (Caricchi et al., 2021; Seropian et al., 2021), while pre-eruptive crystallinity affects buoyancy-driven outgassing (Parmigiani et al., 2017). Just as important for hazard assessment is the reservoir geometry. The spatial distribution of melt can be used to estimate the magma recharge rate and the likely volume of future eruptions.

\section{Need for high-resolution imaging of volcanoes}

While petrology gives invaluable insights into thermal evolution and ascent history of magma (e.g. Druitt et al., 2012), constraining reservoir geometry and current storage conditions under active volcanoes requires geophysical imaging. Seismic tomography has provided strong evidence for partial melting beneath many active volcanoes and has helped constrain magma storage depths and volumes (e.g. Paulatto et al., 2012; Ward et al., 2014; Heath et al., 2015; Kiser et al., 2018; McVey et al., 2020). The seismological evidence is broadly consistent with low melt fraction storage (Lees, 2007), but the inherent resolution limits (Malcolm and Trampert, 2011) lead to significant over- and under-estimation of a reservoir's volume and melt fraction, respectively. Although the evidence for crystal mush reservoirs seems compelling, the picture is far from complete. It is unclear whether magma can be rapidly extracted from crystal mush and directly erupted or whether it must first accumulate in high melt fraction magma chambers or lenses (Sparks et al., 2019). The question of how eruptible magma can be extracted from mush reservoirs is also hotly debated (Holness, 2018). Persistent melt lenses may have been overlooked provided they are smaller than the resolution limits of the geophysical methods used to date. Such 'covert' melt lenses have been drilled at $\sim 2 \mathrm{~km}$ b.s.l. at several volcanoes (Rooyakkers et al., 2021). Although their prevalence is unknown, they may pose a significant hazard, affecting the availability of eruptible magma.

Traditional seismic imaging methods are unsuitable for addressing these questions since they lack the resolution required to detect melt lenses. We show that full-waveform inversion (FWI) can overcome this limitation and can provide robust constraints on melt fraction. FWI is well-suited for detecting crustal magma (Morgan et al., 2013), but requires dense sources and/or receivers. Focusing on a submarine volcano has the advantage of dense marine seismic acquisition. Our method can achieve a resolution of a few hundred metres, enough to detect small melt lenses that have so far remained beyond reach (Morgan et al., 2013). 


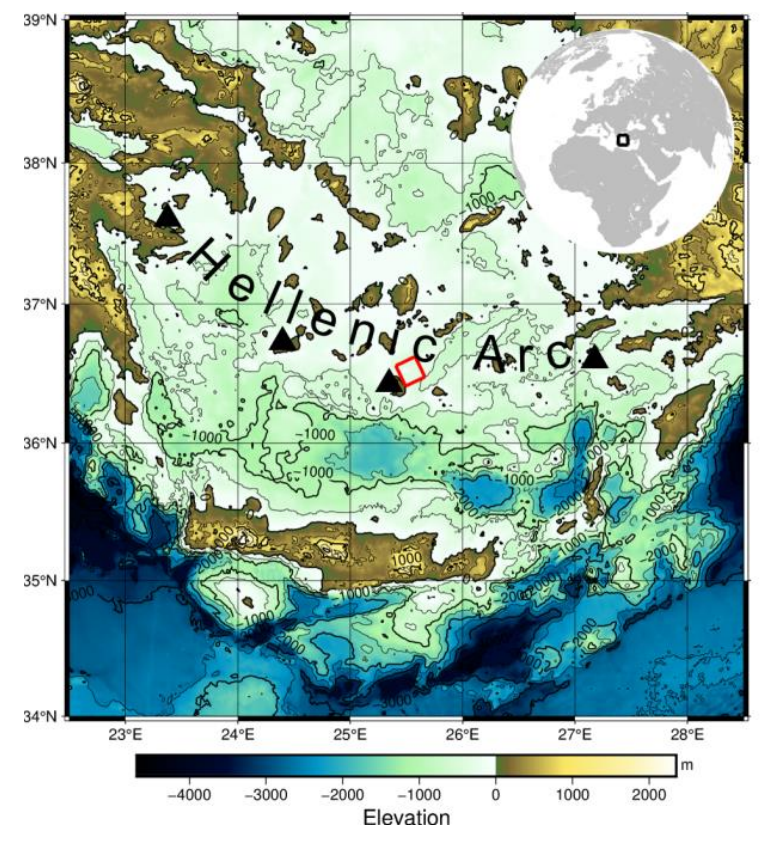

(a)

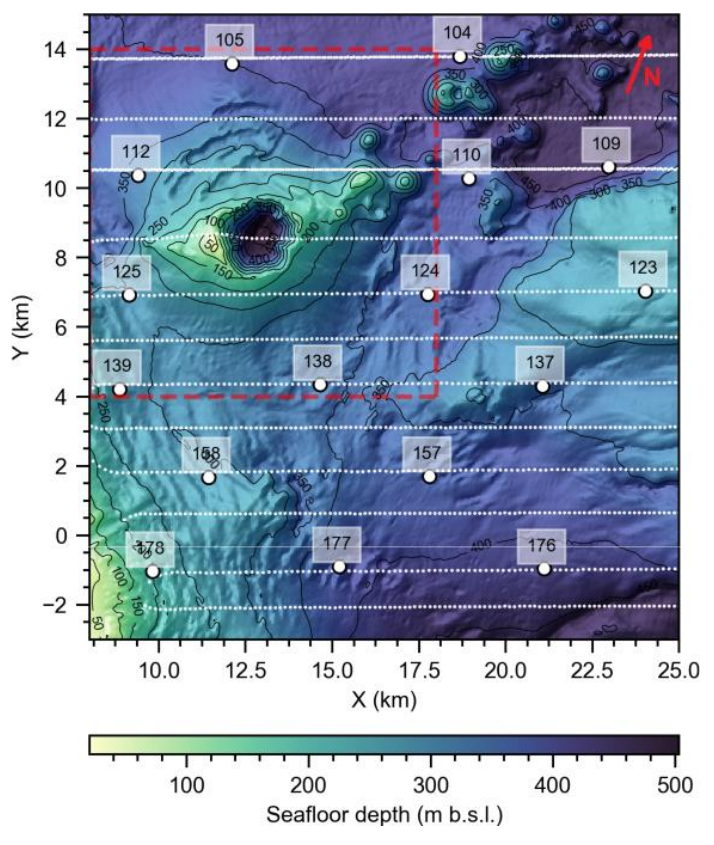

(b)

Figure 1: Study area \& data-acquisition geometry. (a) Regional topography around the Hellenic arc; black triangles denote active volcanic centres - from W to E: Methana, Milos, Santorini and Nisyros. (b) Acquisition geometry in local coordinates (see Methods); annotated white circles ocean-bottom seismometers and their IDs; white dots - airgun shots; red square - zoomed area shown in fig. 2.

\section{Seismic imaging at Kolumbo volcano}

Here, we use full-waveform seismic imaging to study Kolumbo, an active submarine volcano located in the Santorini volcanic field (SVF), along the Hellenic Arc (fig. 1a). Kolumbo is the most active centre of seismic (Bohnhoff et al., 2006; Dimitriadis et al., 2009; Andinisari et al., 2021; Schmid et al., 2022) and high-temperature hydrothermal activity within the SVF (Sigurdsson et al., 2006; Hübscher et al., 2006; Kilias et al., 2013; Carey et al., 2013; Rizzo et al., 2016). It last erupted in 1650 AD in a highly explosive, tsunamigenic event (Ulvrova et al., 2016) which produced a few $\mathrm{km}^{3}$ of hydrous, biotite-rich rhyolitic lava (Cantner et al., 2014; Konstantinou, 2020). Despite the high heat and gas fluxes (Rizzo et al., 2019) which suggest an elevated magmatic activity, little is known about the underlying magmatic system. Local-earthquake tomography showed a 5\%-reduction in S-wave velocity at 5-7 km b.s.l. (Dimitriadis et al., 2010). Its interpretation as a magma chamber was utilised in petrological (Cantner et al., 2014) and numerical studies (Konstantinou, 2020). Active-source travel time tomography does not detect a significant anomaly in the uppermost $6 \mathrm{~km}$, (McVey et al., 2020), with just a reduction of $3 \%$ in P-wave velocity at 2-4 km b.s.l. directly below the edifice (Hooft et al., 2019).

We apply acoustic isotropic full-waveform inversion (Tarantola, 1984; Morgan et al., 2013) to a 3D wideangle, multi-azimuth seismic dataset (Hooft et al., 2017) consisting of early arriving waves generated by densely-spaced airgun shots and recorded by 16 ocean-bottom seismometers (fig. 1b). We refine the starting model from travel-time tomography (Heath et al., 2019) by running 160 iterations of qualitycontrolled waveform-misfit optimisation, increasing maximum frequency of waveforms by $0.5 \mathrm{~Hz}$ every 20th iteration, reaching $6.5 \mathrm{~Hz}$ in the last iteration block. Then we use the effective-medium theory to interpret the low P-wave velocity anomaly under Kolumbo in terms of melt-filled porosity and estimate the approximate volume of melt stored in the reservoir. 
The main result of this study is a P-wave velocity model of the subsurface at and around Kolumbo. The model is constrained to a $17 \times 18 \mathrm{~km}$ horizontal domain (fig. 1b) and stretches down to $4 \mathrm{~km}$ below sea level, sampled regularly at a $50-\mathrm{m}$ interval. Synthetic waveforms calculated through this model match the observed data much better than for the starting model and the inversion converged to a waveformmisfit minimum (fig. 5 of Extended data).

\section{Kolumbo low-velocity anomaly}

The most striking feature of the final model is a prominent low-velocity zone (LVZ) beneath Kolumbo extending from 2.1 to at least $4 \mathrm{~km}$ b.s.l., with a diameter of $0.6 \mathrm{~km}$ for the $4 \mathrm{~km} / \mathrm{s}$ contour and a minimum value of $3.4 \mathrm{~km} / \mathrm{s}$ at $2.55 \mathrm{~km}$ b.s.I. (40\% reduction relative to the starting model, see below). To highlight its geometry, we display it as a negative anomaly relative to the starting model, with the absolute values (for both the starting and final model) shown in the insets (fig. 2). Its shape is plume-like in the SW-NE cross-section ( $\mathrm{Y}$ axis), thinner at the base where the wavelength is larger, and thus not produced by the directional smoothing which we used to regularise the inversion (see Methods). The regularisation leads to recovery of only $80 \%$ of the true amplitude as shown by synthetic tests (fig. 10 of Extended data). The maximum recovered anomaly was $1.6 \mathrm{~km} / \mathrm{s}$ relative to the starting $5.0 \mathrm{~km} / \mathrm{s}$ (fig. 2). Correcting for regularisation gives approximately a $2.0 \mathrm{~km} / \mathrm{s}$ anomaly (40\% reduction), corresponding to a P-wave velocity of $3.0 \mathrm{~km} / \mathrm{s}$ within the LVZ.

(a)

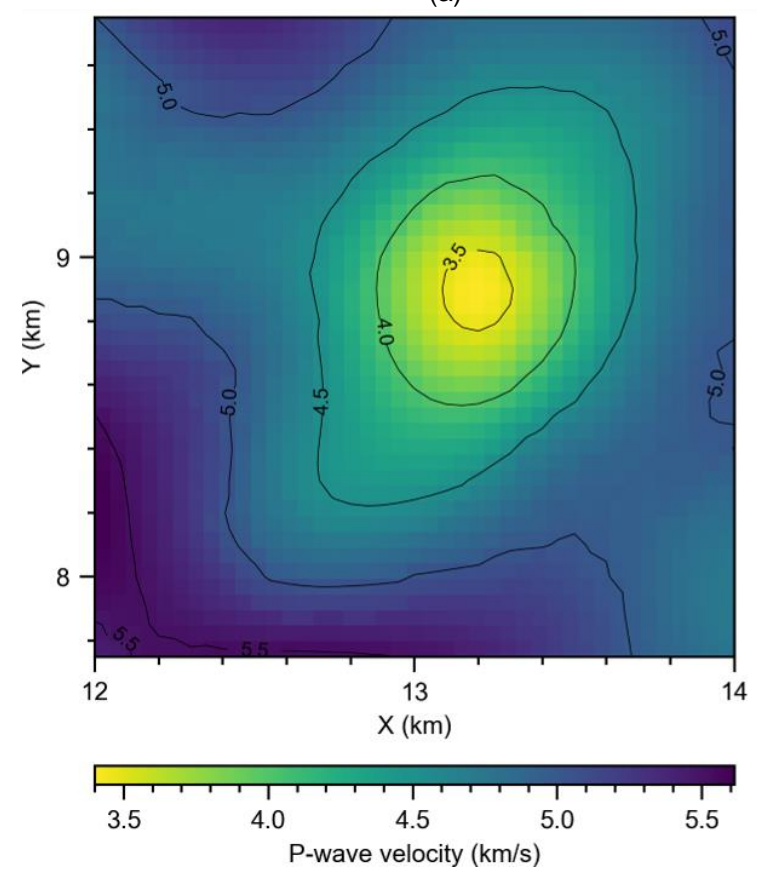

(c)

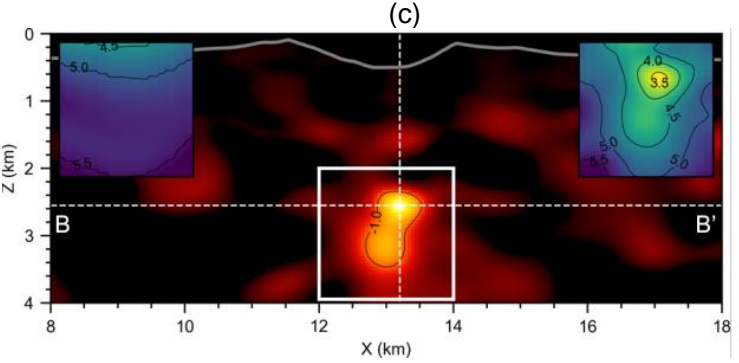

(b)

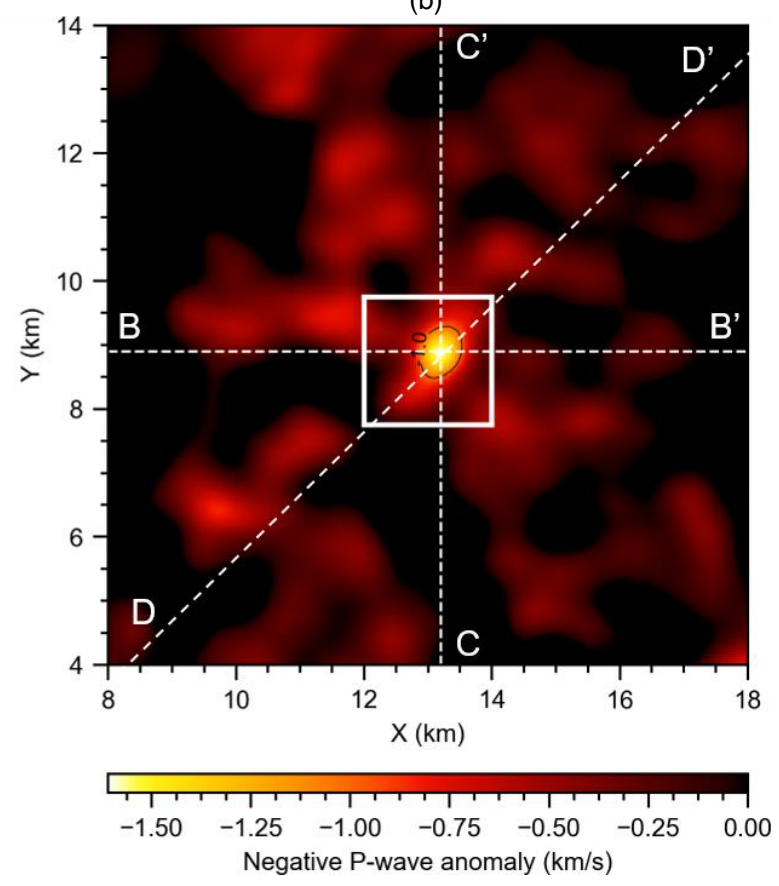

(d)

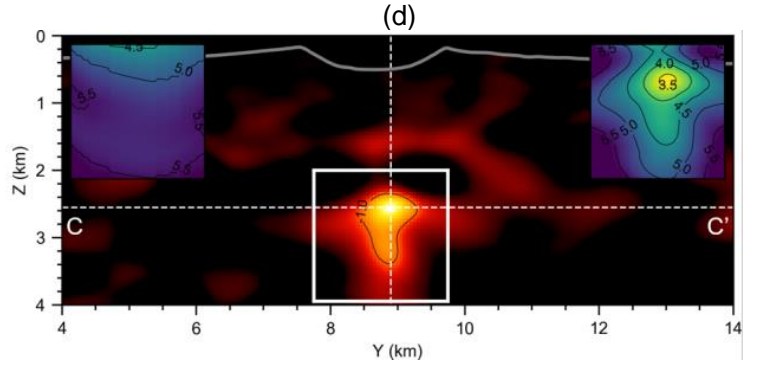

Figure 2: Final P-wave velocity model. Shown as a negative anomaly relative to the starting model. Insets: Absolute values of the starting and final model (left and right, respectively) inside the reservoir denoted by the white box. Dashed lines indicate cross-section planes. 


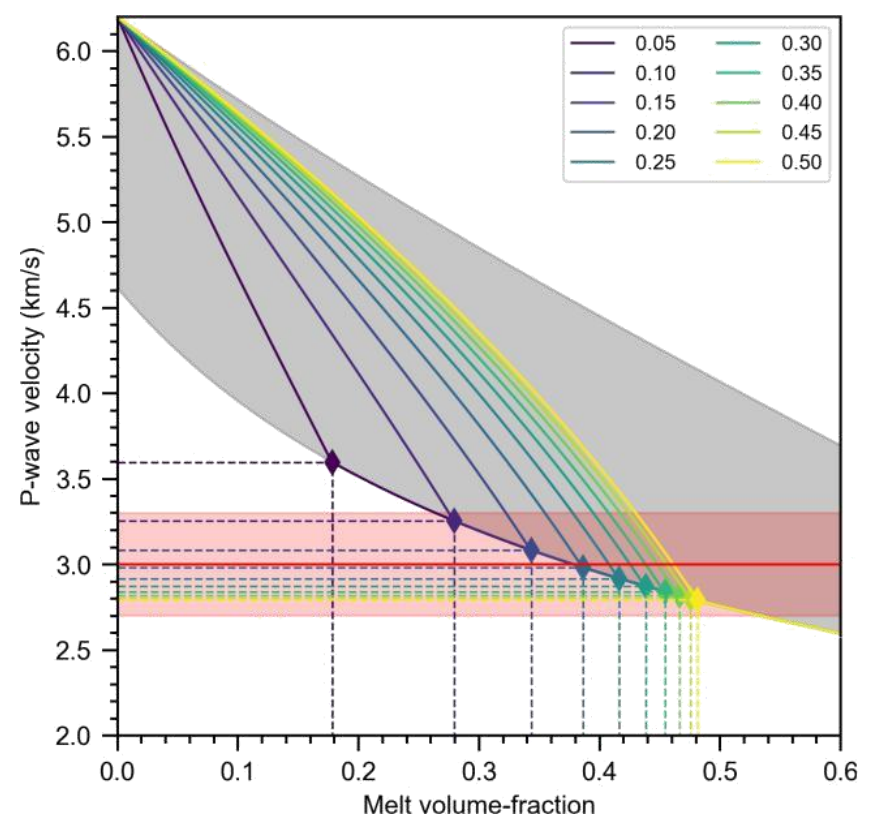

Figure 3: P-wave velocity of a granitic intrusion as a function of melt fraction. Grey area fills between the Hashin-Shtrikman bounds (Hashin and Shtrikman, 1963). Coloured lines correspond to different values of the pore aspect ratio listed in the key, with rhombi marking the critical porosity (Nur et al., 1998). The maximum observed anomaly with 3 error bounds from jackknifing is denoted in red.

\section{Credibility and fidelity of recovery}

Several factors make this anomaly a robust feature required by the data. First, the synthetic tests show that a similar anomaly is recoverable by our method (fig. 10 of Extended data). Second, the anomaly, although much more smeared, was already present in the high-quality starting model (fig. 6 of Extended data) obtained by travel-time tomography (Heath et al., 2019), which has lower resolution but is more robust against artifacts compared to full-waveform inversion (Virieux and Operto, 2009). Third, the largest enhancement of the anomaly amplitude, corresponding to the largest improvement of waveform fit, was achieved during the first, low-frequency iterations, indicating that the anomaly is not produced by over-fitting of the high-frequency waveforms. Fourth, the feature is robust against different inversion strategies and data subsets. In particular, jackknife resampling shows that it is not caused by potential outliers (fig. 9 of Extended data). Although the recovered final model is likely to have errors due to data noise, inversion regularisation, and the simplified physics (acoustic, isotropic, non-attenuative medium) used to calculate synthetic data, we argue that these errors are small and do not affect our conclusions (Supplementary Information).

\section{Melt fraction and melt volume}

The observed low-velocity anomaly can be explained by the presence of either melt or hydrothermal fluids (magmatic gases and/or seawater). We favour the former possibility based on independent seismic reflection observations of the hydrothermal system that place the top of the hydrothermal reservoir at $\sim 0.6 \mathrm{~km}$ b.s.l. (Hübscher et al., 2006). Geochemical analysis of the hydrothermal fluids suggests that interaction of magmatic gases and seawater occurs at $\sim 1 \mathrm{~km}$ b.s.l. (Rizzo et al., 2019). The hydrothermal system is not visible in our model because the shallow structure is poorly constrained by the data (see fig. 9 and 10). Nonetheless, the weak low-velocity layer at 1.4-1.9 km b.s.l. may be evidence of a volatile-rich lens. Although a multi-level hydrothermal system extending to the base of the observed anomaly is conceivable, the persistent seismic unrest down to $16 \mathrm{~km}$ b.s.l. (Schmid et al., 2022) makes this possibility less likely, as explained below. 
We can also rule out the hypothesis that the LVZ is caused by a purely thermal anomaly. The temperature required to explain such a strong velocity perturbation greatly exceeds the solidus temperature for granite, implying partial melting (see Methods). We interpret the LVZ as a partially molten intrusion and we assume it to be granitic (rhyolitic) based on the bulk composition of lava from the 1650 AD eruption (Cantner et al., 2014).

We estimate the maximum melt fraction of the intrusion by comparing the maximum observed P-wave velocity anomaly of $3.0 \mathrm{~km} / \mathrm{s}$ with values calculated for partially molten granite using the self-consistent effective medium approach (Berryman, 1980), assuming melt-filled spheroidal pores (see Methods). There is a strong trade-off between the pore geometry (aspect ratio) and melt fraction. Here we assume thin, oblate pores (melt films) of aspect ratio between 0.05 and 0.5 (Takei, 2002). Recalling the uncertainty in velocity of $0.3 \mathrm{~km} / \mathrm{s}$ (from jackknifing) yields melt fractions ranging from 0.26 to 0.53 (fig. 3). Assuming the velocity error to be normally distributed (with $\sigma=0.1 \mathrm{~km} / \mathrm{s}$ ), the melt fraction is $0.42 \pm$ 0.04 .

The total volume of the low-velocity anomaly equals $6.2 \mathrm{~km}^{3}$, which corresponds to a sphere of $1.1 \mathrm{~km}$ radius. This is probably a lower bound, as the anomaly seems to extend below the bottom of the model. The total volume of melt stored in the reservoir is $(1.38 \pm 0.32) \mathrm{km}^{3}$, where the error bounds come from the aspect-ratio uncertainty.

\section{Relationship with seismic activity}

A recent seismicity study by Schmid et al. (2022) shows that the observed anomaly coincides with the tip of a cone-shaped region hosting enhanced seismic activity in the 2006-2007 period. The earthquakes were clustered in several swarms starting with the strongest events at 6-9 depth and migrating upwards, terminating at the base of the LVZ. The swarm propagation was faster than expected for hydrothermal gases diffusing from a point source or for active diking (Schmid et al., 2022). However, the speed and focal mechanisms associated with the swarms remain consistent with melt ascent along pre-existing, subvertical pathways through a rheologically strong layer at 4-9 km b.s.l. Schmid et al. (2022) interpret this seismic activity as a result of either transport of melt from larger depths to the observed reservoir, or formation of fractures enabling such transport which occurred after the recording period. These findings support our interpretation of a melt-filled reservoir below Kolumbo. Similar seismic activity has been recorded during several other time periods (Bohnhoff et al., 2006; Dimitriadis et al., 2009; Andinisari et al., 2021) suggests ongoing reservoir recharge by frequent injections of magma from greater depth.

\section{Magma chamber versus mush}

The melt fraction of $0.42 \pm 0.04$ at the centre of the velocity anomaly may be overestimated by neglecting the $6 \%$ of volatiles reported for the 1650 AD eruptive products (Cantner et al., 2014). However, it is likely above the critical porosity (fig. 3) corresponding to the mush-magma transition (Sparks et al., 2019), implying rheology controlled by melt rather than crystalline framework. The observed $>40 \%$ reduction of $\mathrm{P}$-wave velocity relative to the regional average is larger than for anomalies obtained by travel time tomography at other volcanoes studied to date. For example: 10\% for Newberry (Heath et al., 2015), Yellowstone (Huang et al., 2015) and Mt. St. Helens (Kiser et al., 2018), 17\% for Montserrat (Paulatto et al., 2019), and $21 \%$ for Santorini (McVey et al., 2020). For this reason, despite the remaining uncertainty in melt fraction, we interpret the imaged reservoir as a small magma chamber rather than a mush zone, or a hybrid reservoir in which a small magma chamber is embedded in a larger mush zone.

Petrological (Cantner et al., 2014) and numerical models (Konstantinou, 2020) of the Kolumbo magmatic system have been based on the interpretation of the low S-wave velocity anomaly from local-earthquake tomography (Dimitriadis et al., 2010), which is located $5-7 \mathrm{~km}$ b.s.l., offset from the edifice. This 
interpretation is inconsistent with the seismicity data (Schmid et al., 2022) which suggests that the source of melt feeding the shallow chamber may be located deeper than $9 \mathrm{~km}$ b.s.l., beneath a rheologically strong, seismically-active layer (Schmid et al., 2022). The composition of the ascending melt is at least partially mafic, as indicated by the enclaves present in the 1650 AD lavas (Cantner et al., 2014; Klaver et al. 2016). We propose that a persistent ascent of mafic melt from deeper levels leads to heating up and remobilisation (Burgisser and Bergantz, 2011) of the shallow felsic melt reservoir, and consequently to formation of a magma chamber.

We propose that the imaged shallow melt reservoir (fig. 4) represents the uppermost level of a multilevel system. Surprisingly, the imaged melt reservoir is not sill-like. While its broad top results from magma ponding below the high-temperature hydrothermal system venting (Sigurdsson et al., 2006; Hübscher et al., 2015; Rizzo et al., 2016), the narrow base reflects the predominant path of magma supplied through a rheologically strong layer (Schmid et al., 2022) that overlies a yet-to-be-imaged deeper mush zone. These results indicate a more complex multi-level system than numerical

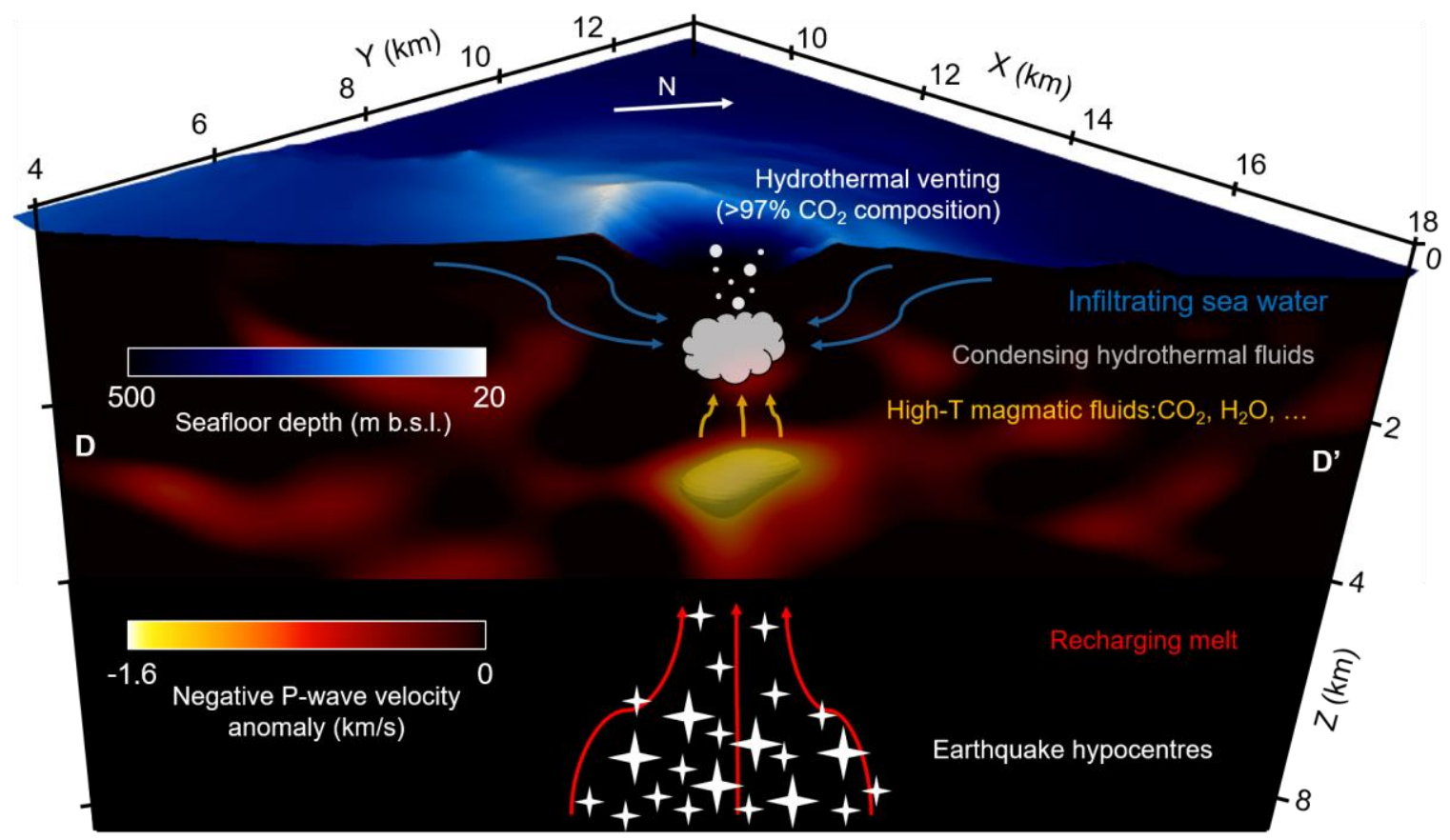

Figure 4: Kolumbo magmatic system. Ascending rhyolitic melt replenishes the shallow chamber. The exsolved gases mix with sea water and vent at the crater floor. The depth of hydrothermal systems is inferred from seismic-reflection images (Hübscher et al., 2015) and geochemical data (Rizzo et al., 2019). The approximate earthquake locations are based on Schmid et. al. (2022). The velocity anomaly is extracted from the final model along the DD' profile (fig. 2b). No vertical exaggeration is applied.

simulations which show small (hundreds of metres) magma chambers forming directly at the top of larger (kilometres) mush zones (Jackson et al., 2018; Booth et al., 2019).

\section{Long-term evolution and present state}

The long-term evolution of a magma chamber depends on the time-scales of melt injection, cooling, and viscous relaxation of the surrounding crust (Degruyter and Huber, 2014). For a chamber to grow, mass injection must be faster than cooling, but slower than the viscous relaxation of elastic stress. Assuming that all of the observed melt has accumulated since the last eruption (1650 AD) and taking $2600 \mathrm{~kg} / \mathrm{m}^{3}$ as the mafic melt density (Konstantinou, 2020), the average melt flux is equal to $4 \times 10^{3} \mathrm{~km}^{3} \mathrm{yr}^{-1}$, or 330 
$\mathrm{kg} / \mathrm{s}$. This is of the same order of magnitude as the estimate for Montserrat (Annen et al., 2013) and nearby Santorini (Parks et al., 2012). Calculations of eruption frequency of upper crustal silicic magma chambers using the approach of Degruyter and Huber (2014) suggest that this flux can result in tens of eruptions before mechanical lock-up, for chamber volumes of up to $20 \mathrm{~km}^{3}$ and for fluxes as small as 50 $\mathrm{kg} / \mathrm{s}$ (Fig. 11 of Extended data).

The volume of mobile magma beneath Kolumbo is up to $0.02 \mathrm{~km}^{3}$ (assuming a pore aspect-ratio of 0.05). This is twice the volume of magma injected in 2011-12 beneath Santorini (Parks et al., 2012). The total volume of melt accumulated in the reservoir beneath Kolumbo $\left(\sim 1.4 \mathrm{~km}^{3}\right)$ is close to the $\sim 2$ $\mathrm{km}^{3}$ of dry-rock equivalent (DRE) volume of the last eruption (Nomikou et al., 2014). For comparison, the DRE volume of the Mt. St. Helens 1980 eruption was $3 \mathrm{~km}^{3}$ (Kiser et al., 2018). The eruption recurrence interval at Kolumbo is unknown, as only the last of five recognised eruptive phases has been dated with confidence (Nomikou et al., 2016). A sequence stratigraphic analysis indicates that all these phases occurred during the last $1.2 \mathrm{Ma}$, suggesting an average recurrence interval of $\sim 240$ ka (Preine et al., 2021). A lower bound of 10 ka was proposed based on seismic reflection data and the tectonic history of the region (Hübscher et al., 2015). While this implies a considerably longer recurrence time than the interval since Kolumbo's last eruption, a sizable lens of mobile melt $\sim 2 \mathrm{~km}$ below the seafloor poses a serious threat of a highly explosive, tsunamigenic eruption in the near future. The high melt fraction implies that the reservoir could be readily mobilised by a larger influx of magma or an external trigger (Caricchi et al., 2021). The shallow reservoir depth lowers the critical overpressure needed to form and propagate a dyke to the eruptive vent (Jellinek and DePaolo, 2003). The relatively shallow water (500 $\mathrm{m}$ at the crater floor) is likely to enhance rather than suppress explosivity (Dürig et al., 2020). A tsunami and an eruptive column of tens of $\mathrm{km}$ with significant ashfall and extensive pumice rafts can be expected as the aftermath of the eruption (Nomikou et al., 2014; Kusky, 2022). Although it will probably be an order of magnitude less powerful than the recent Hunga Tonga-Hunga Ha'apai event, it may have a greater impact, considering $\mathrm{CO}_{2}$ accumulated at the crater floor (Carey et al., 2013), the dense population on nearby Santorini, and the sea/air traffic in the Aegean.

\section{A new era of volcano imaging}

Our study is the first application of active-source, seismic full-waveform imaging to an active volcano. High-resolution imaging combined with high-sensitivity earthquake monitoring (Schmid et al., 2022) provides unique evidence for magma transport to the shallow crust and a direct image of the resulting magma chamber beneath Kolumbo volcano. The current state of the reservoir indicates that an explosive eruption of high societal impact in future is possible (though not imminent), thus we suggest establishing a permanent observatory involving continuous earthquake monitoring (Schmid et al., 2022) and seafloor geodesy.

Our image bridges the gap between seismic data and conceptual models of relatively small but highmelt fraction silicic bodies forming at the uppermost level of transcrustal mush systems. Remarkably, the chamber was almost entirely missed by dense travel-time tomography (Heath et al., 2019; McVey et al., 2020), which used the same active-source dataset. Similar melt reservoirs would have gone undetected at other active volcanoes, raising the possibility that they may be more common than previously thought. Further thermomechanical modelling should give insights into the formation and longevity of such chambers.

Wider adoption of full-waveform imaging may usher a new era of volcano geophysics, increasing detectability of melt reservoirs by providing detailed images of elastic parameters, as well as more accurate background models for earthquake relocation and 3D seismic migration (Magee et al., 2018). Increasingly tight constraints on the spatial distribution of melt and volume of eruptible magma in the 
shallow crust will substantially improve our understanding of magmatic systems and revolutionise volcanic hazard assessment.

\section{Acknowledgements}

Data used in this research were provided by instruments from the Ocean Bottom Seismograph Instrument Pool (http://www.obsip.org) which is funded by the National Science Foundation. The Geophysical Instrument Pool Potsdam provided 60 land seismometers. The Aristotle University of Thessaloniki contributed five land seismometers and the Greek military donated helicopter time for installations on the smaller islands. The data collection was funded by the National Science Foundation grant number OCE-1459794 to the University of Oregon. The data analysis was funded by Leverhulme Trust grant RPG-2015-363 to Imperial College London. FS received funding from Deutsche Forschungsgemeinschaft, grant 453685621 . MP was funded by a NERC Independent Research Fellowship (NE/R015708/1). KC dedicates this paper to the memory of Prof. Marek Grad.

\section{Data availability}

The entire OBS dataset analysed in this study has been archived at the IRIS Data Management Center (http://www.iris.edu).

\section{Code availability}

The FULLWAVE3D software used to invert the data can be accessed through academic collaboration with Imperial College London or a membership of the FULLWAVE consortium (Warner et al , 2013). The effective-medium properties were calculated using the ElasticC package available at http://github.com/michpaulatto/ElasticC. The FWI-diagnostics FullwavePy software used to QC the inversion and produce most of the figures can be downloaded from http://github.com/kmch/FullwavePy. 


\section{Methods}

Data selection \& processing We analysed a subset of data collected in the PROTEUS experiment (Hooft et al., 2017) contained in a $17 \times 18 \mathrm{~km}$ wide box (fig. 1), comprising 16 ocean bottom seismometers (OBSs) and 1505 air-gun shots fired at $\sim 150 \mathrm{~m}$ intervals along the profile lines. The local Cartesian coordinate system was obtained by rotating a local E-N coordinate system centred at $25.3971^{\circ} \mathrm{E}$ $36.4042^{\circ} \mathrm{N}$ by 25.5 anticlockwise. Traces where direct water waves interfere (shot-receiver offset less than $5 \mathrm{~km}$ ) were excluded from the dataset, followed by manual removal of bad-quality traces, resulting in an average of 977 traces per OBS. Each trace was 5-sec. long, sampled at $2.5 \mathrm{~ms}$. The data were filtered with a minimum-phase, frequency-domain, band-pass Butterworth filter of corner frequencies 23-4.5-6.5 Hz followed by muting before, and $1 \mathrm{sec}$. after, first breaks calculated from the starting model (see below).

Full-waveform modelling We used an explicit, time-domain, least-squares-optimised, finite-difference solver of the acoustic, isotropic, 3D wave equation implemented in the FULLWAVE3D package (Warner et al., 2013) with effective accuracy of 6th order in space and 4th order in time. As the number of airgun shots was much greater than the number of OBSs, source-receiver reciprocity was utilised by labelling sources as receivers and receivers as sources. Our starting $P$-wave velocity model was derived by first-arrival travel-time tomography (Heath et al., 2019) and discretised at 50-m interval in all dimensions. The density was calculated at each iteration from that model using an empirical relation (Gardner et al., 1974), except for a constant value in the water. The seabed was modelled implicitly by a velocity contrast. The sea surface was simulated as a flat, planar free surface located one node above the top of the model grid. Absorbing boundaries (Cerjan et al., 1985) of $2.5-\mathrm{km}$ width were used elsewhere. A single-source wavelet assigned to all shots was extracted from the data by deghosting stacked, high-quality, near-offset traces using an initial-guess wavelet and a Wiener filter.

Full-waveform inversion A least-squares misfit between synthetic and field data, both normalised by their respective norms, was minimised with a steepest-descent algorithm preconditioned by an approximation of the diagonal Hessian of the misfit function (Warner et al., 2013). Both the misfit gradient and the step-length were calculated using the adjoint method (Lions, 1972; Tarantola, 1984). The regularisation involved smoothing the misfit gradient by a Gaussian filter over 2 (local wavelengths) horizontally and 1 vertically. Both the source wavelet and field data were low-pass filtered at a cut-off frequency increasing by $0.5 \mathrm{~Hz}$ from 3 to $6.5 \mathrm{~Hz}$ across 8 blocks of 20 iterations, totalling in 160 iterations.

Quality control We analysed phase spectra (wrapped between $-\pi$ and $\pi$ radians) of the early synthetic and observed arrivals in order to estimate the $\mathrm{S} / \mathrm{N}$ ratio of the field data and the adequacy of the input and forward modelling (Shah et al., 2012). Phase-residual plots of early synthetic and observed arrivals were used to assess the quality of the starting model, in particular to detect problems with data cycleskipping indicated by abrupt changes from $-\pi$ to $\pi$ (or vice versa) between neighbouring stations (fig. $5)$.

Anomaly recovery tests To assess the effective resolving power of the inversion, in particular to quantify the expected underestimation of velocity anomalies, we performed a suite of spike tests (Rawlinson and Spakman, 2016). We used the same strategy and input as for the field-data inversion. The only difference was replacing the observed data with acoustic synthetics calculated through an ensemble of 12 models constructed by perturbing the starting model with a suite of sphericallysymmetric 3D Gaussian anomalies centred roughly at the observed low-velocity anomaly $(13.25 ; 8.75$; $2.75 \mathrm{~km}$ ), with full widths at half-maximum of $0.2,0.8$ and $1.4 \mathrm{~km}$ and peak amplitudes equal to $1,5,10$ and $50 \%$ of the background model. Only anomalies stronger than $10 \%$ were detectable. The best recovery ( $80 \%$ of the true peak amplitude) was obtained for the $50 \%$ anomaly of $0.8-\mathrm{km}$ width (fig. 10$)$. Anomalies smaller and/or weaker were not recovered. Larger $(1.4 \mathrm{~km})$ but weaker $(10 \%)$ anomalies 
yielded worse recovery than the best case, while the $50 \%$ anomaly of $1.4-\mathrm{km}$ width led to artifacts characteristic of cycle-skipping.

Jackknife resampling To detect potential outliers in the OBS data and quantify the uncertainty of the final model we used jackknife resampling (e.g. Rawlinson et al., 2014). We performed 16 field-data inversions, every time excluding a different OBS from the dataset. The standard deviation of the models recovered after 160 iterations (fig. 9) was taken as a proxy for uncertainty.

Effective-medium calculation We used the self-consistent scheme (Berryman, 1980) to calculate the effective bulk and shear moduli of a two-phase, partially-molten granite with a composition that is the average of 7 rock samples from the most recent Kolumbo eruption (supplement of Klaver et al., 2016). For the solid phase, we used $V_{P}=(6.25 \pm 0.13) \mathrm{km} / \mathrm{s}$, vs $=(3.67 \pm 0.12) \mathrm{km} / \mathrm{s}$, and $\rho=(2660 \pm 20) \mathrm{kg} / \mathrm{m}^{3}$ from the laboratory measurements at $200 \mathrm{MPa}$ and $30^{\circ} \mathrm{C}$ of more than 100 granite samples (Christensen and Stanley, 2003). We corrected the velocities (Christensen, 1979) for lithostatic pressure (66 MPa) and a solidus temperature of $700^{\circ} \mathrm{C}$ (Boettcher and Wyllie, 1968), obtaining $v_{P}=6.20 \mathrm{~km} / \mathrm{s}$ and $v_{s}=3.58$ $\mathrm{km} / \mathrm{s}$. Thus, the temperature effect is a second-order factor and partial melting is required to explain the observed velocity anomaly. For the fluid phase, we use $\rho 2110 \mathrm{~kg} / \mathrm{m}^{3}$ and bulk modulus $\mathrm{K}=8.08 \mathrm{GPa}$ from the thermodynamic model based on the Birch-Murnaghan equation (Ueki and Iwamori, 2016). The assumption underlying the SCS calculation is spheroidal-shaped pores. We use $0.05-0.5$ as the range of plausible aspect ratios (Takei, 2002), due to a lack of experimental constraints. We assumed the lowfrequency, equilibrated limit (Biot, 1956) starting with air-filled pores followed by fluid substitution according to Gassman's equation (Gassmann, 1951). Sensitivity analysis showed that varying input parameters other than pore aspect ratio and fluid bulk modulus (which in turn is sensitive to water content) has a negligible effect on the final result. 


\section{Extended data}

Additional data supporting the main text are presented in fig. 5-11.

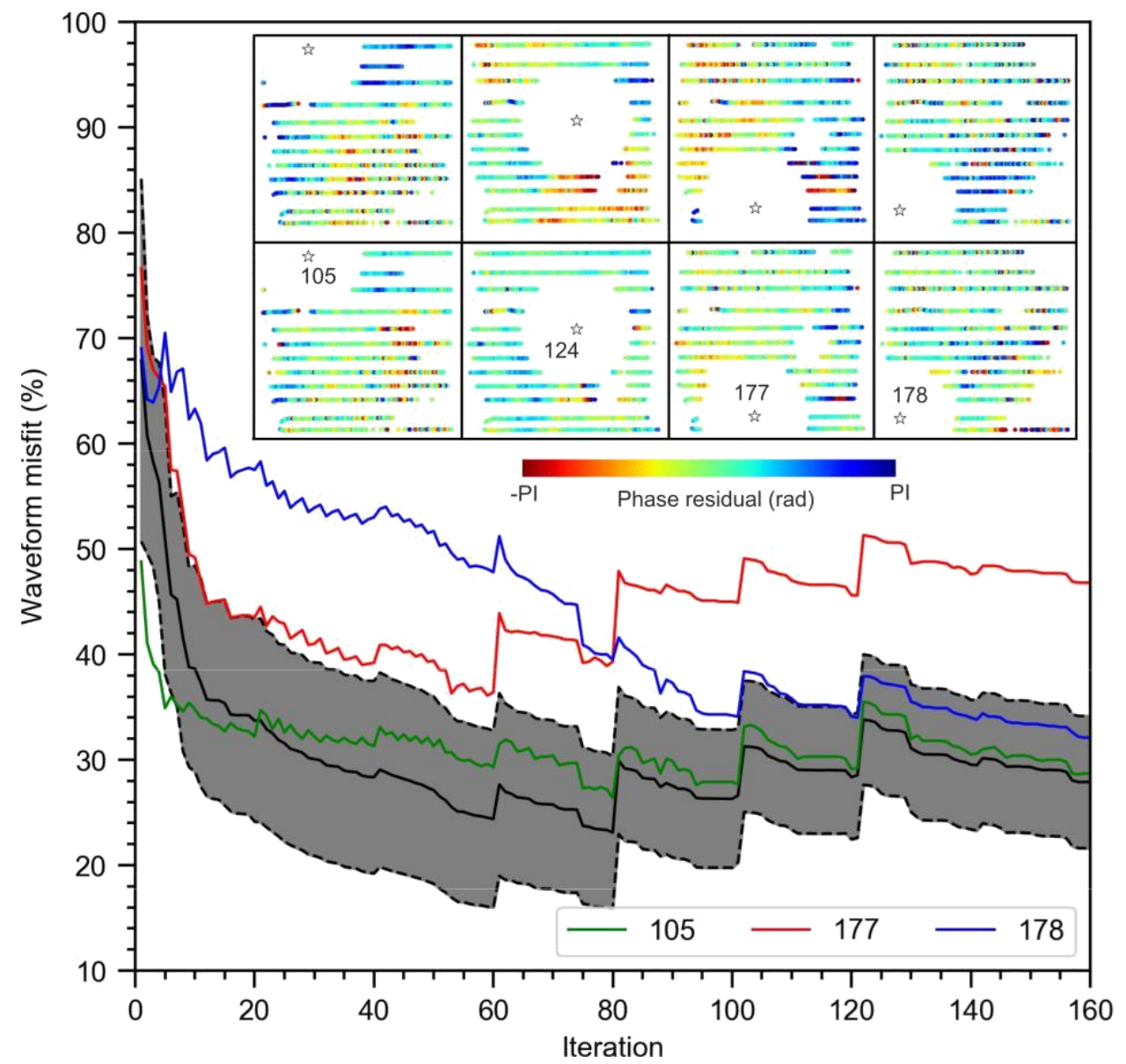

Figure 5: Data-misfit across iterations. Objective function defined as $L^{2}$-norm misfit of normalised waveforms, averaged over OBSs, shown as a black line between 1 grey bounds; stations 177 and 179 with the largest misfit, along with a more typical station 105, are highlighted in colour; inset: phase residual of four OBSs (annotated stars) at $3 \mathrm{~Hz}$ for starting (top) and final (bottom) model. 

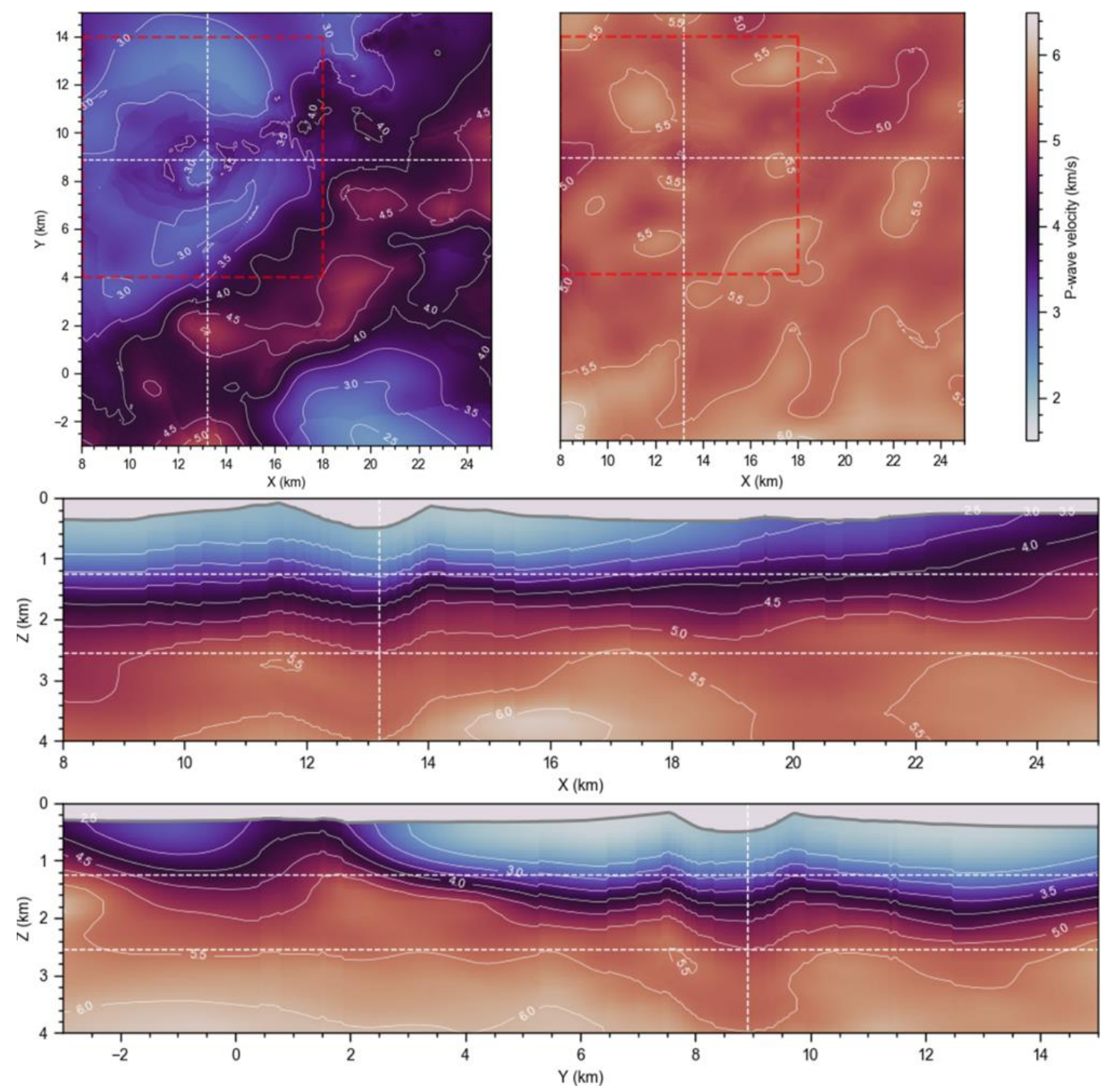

Figure 6: Starting model. Red square - zoomed area shown in fig. 2. White dashed lines indicate crosssection planes. Top-right slice was cut at $2.55 \mathrm{~km}$ b.s.l. 

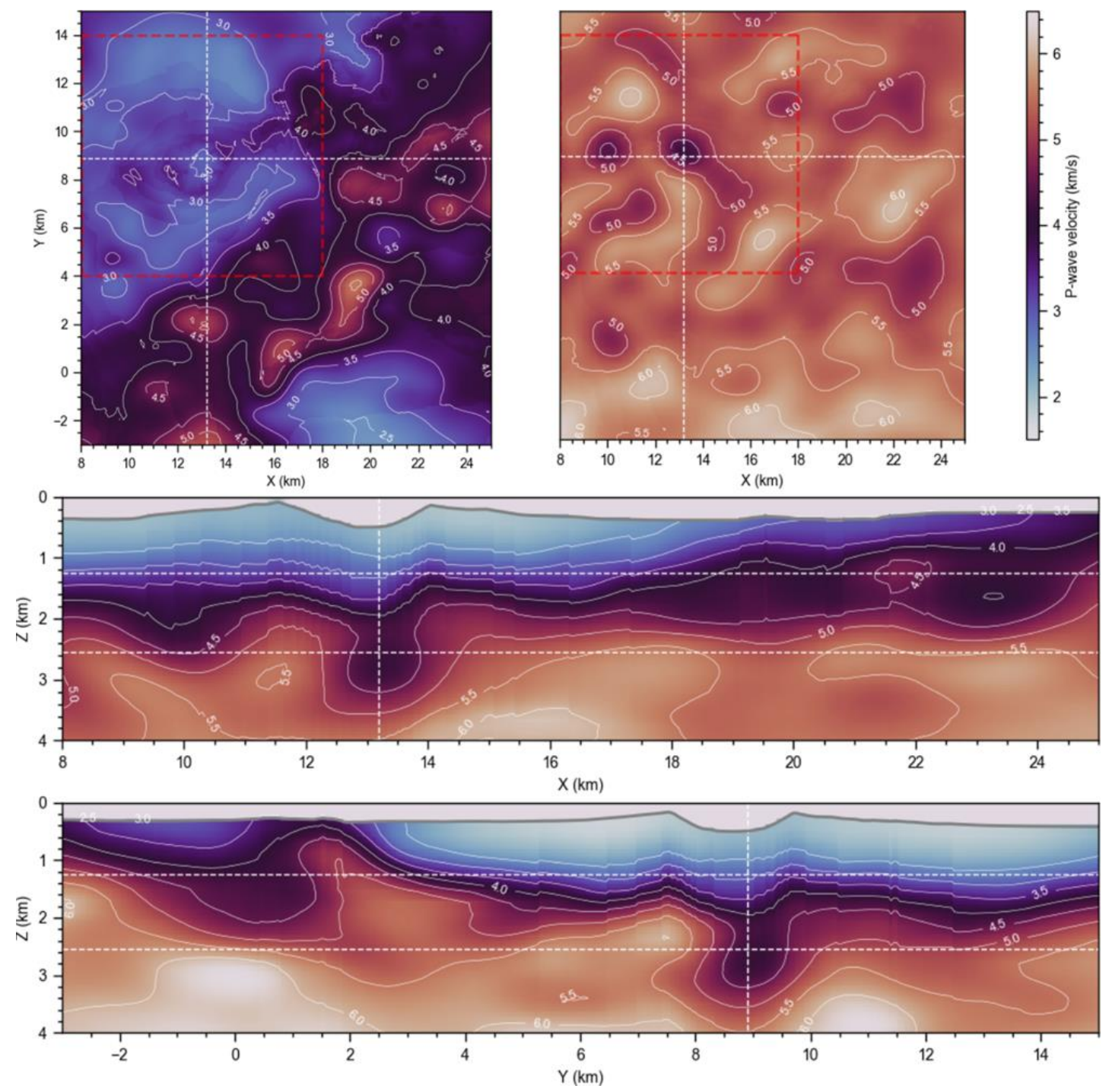

Figure 7: Model after 20 iterations. See caption of fig. 6 for additional information. 

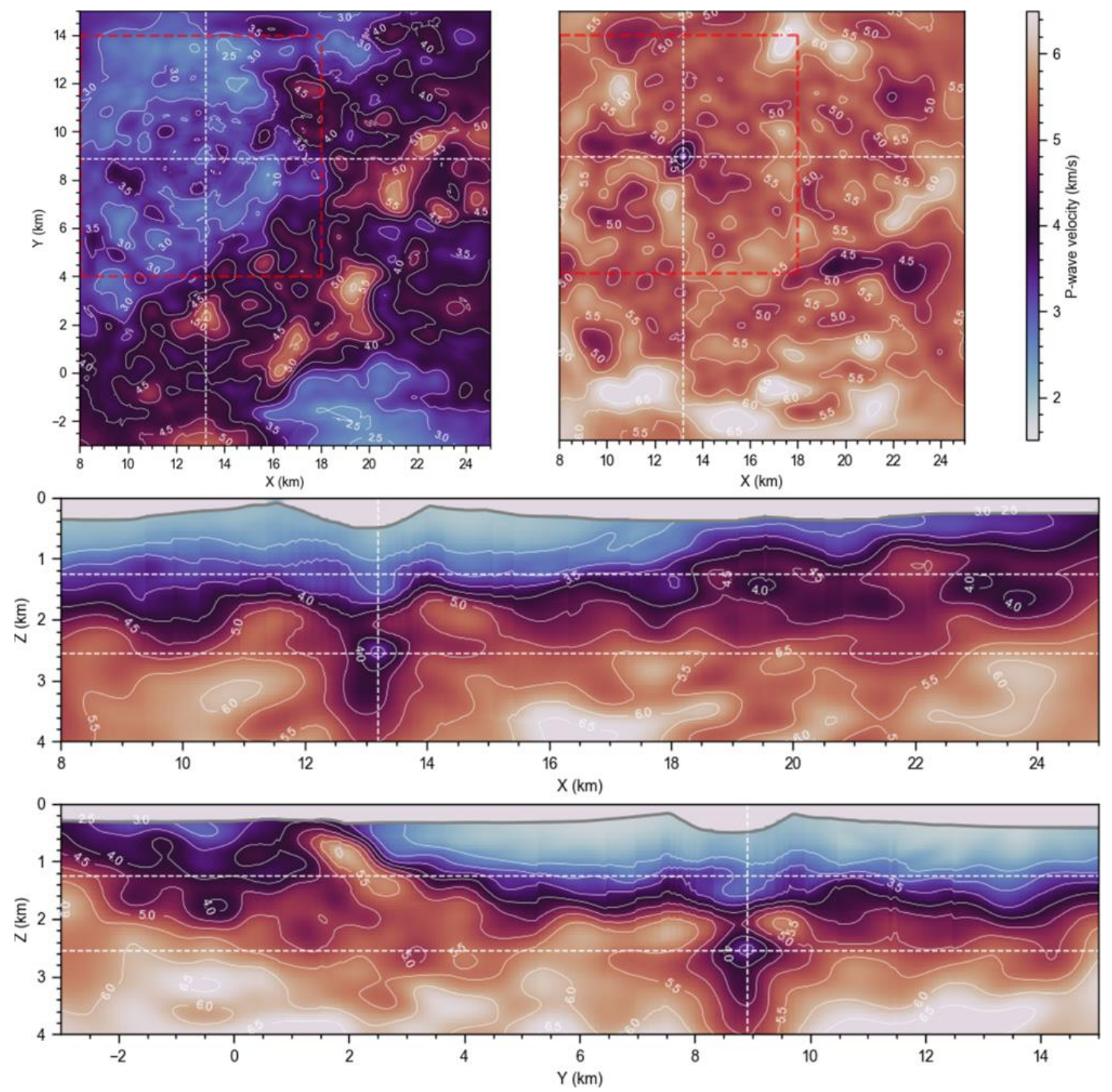

Figure 8: Final model. See caption of fig. 6 for additional information. 

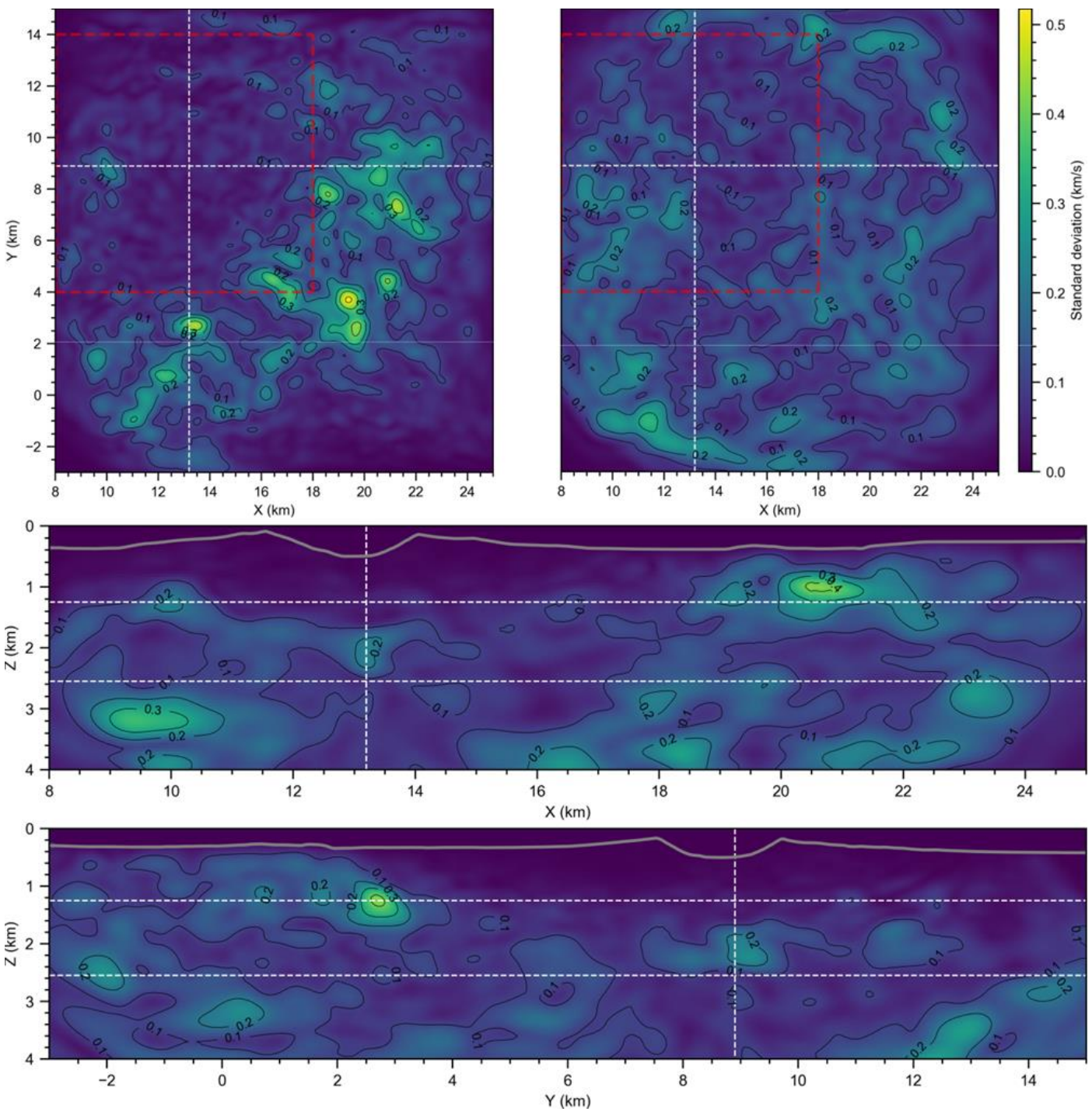

Figure 9: Final model error. Standard deviation of ensemble of final models from 16 jackknife-resampling inversions; red square - zoomed area shown in fig. 2; white dashed lines indicate cross-section planes; topright slice was cut at $2.55 \mathrm{~km}$ b.s.l. 

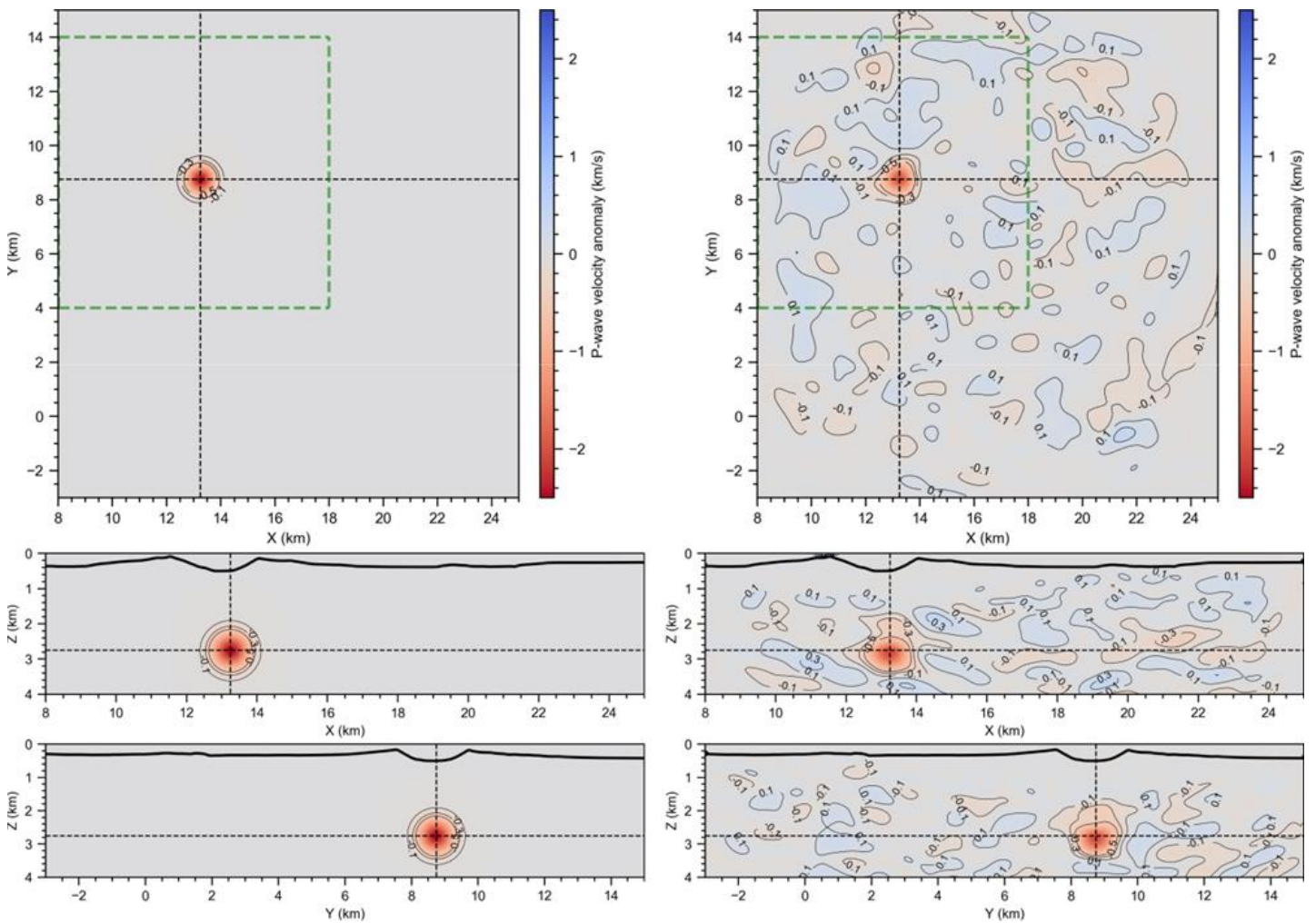

Figure 10: Results of synthetic anomaly recovery test. Left/right: original/recovered anomaly. Only $80 \%$ of the amplitude at the centre of anomaly was recovered.

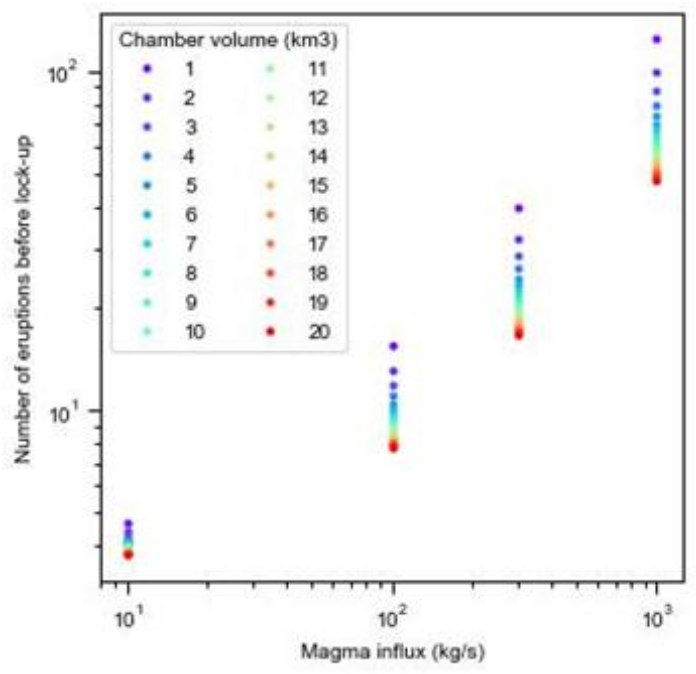

Figure 11: Number of eruptions from a magma chamber as a function of the melt influx and chamber volume. The relationship was calculated from the model for eruption frequency of upper crustal silicic magma chambers (eq. 45 of Degruyter and Huber, 2014), under the assumptions described therein. The model accounts for mass injection, viscous relaxation, cooling, crystallisation, gas exsolution, and eruption. The values are averages over $10^{6}$ Monte Carlo runs which sampled Gaussian distributions of overpressure equal to $p=(20 \pm 15) \mathrm{MPa}$ (Konstantinou, 2020), crust viscosity equal to $\log _{10}=(20.5 \pm 1.5) \log _{10}$ (Pa s) (Konstantinou, 2020), and thermal diffusivity equal to $(3.0 \pm 0.5) 10^{6} \mathrm{~m}^{2} / \mathrm{s}$, where the uncertainties correspond to $3 \sigma$ of the respective distributions. This thermal diffusivity is relatively high (Whittington et al., 2009) and was motivated by the cold upper crust and efficient heat removal via the hydrothermal system at Kolumbo. 


\section{Supplementary information}

Below we provide additional comments to the main text and the figures of Extended data. More details on the experiment set-up, data processing, and effective-medium calculation can be found in the PhD thesis (chapters 3, 7, and 8, respectively) of the first author (Chrapkiewicz, 2021).

Waveform misfit across iterations We use the objective function and phase plots to quality control the results on a shot-by-shot basis. On average, there is a decrease of about 0.30 rad in RMS phase residual at $3 \mathrm{~Hz}$ across 80 iterations. For all stations, and for each iteration block, the residual decreased between the first and last iteration (fig. 5). The reduction in phase residual was smaller for the higher frequencies, which is consistent with the observed changes in the objective function (fig. 5). At $3 \mathrm{~Hz}$, the best improvement of 0.70 rad drop from 1.51 to 0.81 rad was for station 157 , second best a 0.60 rad drop from 1.46 to 0.86 rad was for station 139 , and the worst, of 0.16 rad drop from 1.24 to 1.08 rad., was observed for station 104 .

Physical model and data noise We argue that the simplified physics used to calculate the synthetic data does not severely affect the recovered P-wave velocity. First, the acoustic approximation seems valid as the shots were fired in water and most energy generated was compressional waves. Synthetic tests show that elastic effects are not a critical factor in acoustic inversion of marine data (Mulder and Plessix, 2008). Second, the study area is characterised by very weak $(<5 \%)$ anisotropy of P-wave velocity (Heath et al., 2021). Thus, the isotropic approximation most likely led to an insignificant error in the anomaly position, without affecting its amplitude (Štekl et al., 2010). Third, attenuation is not a firstorder factor which would drive inversion of early-arriving data (Warner et al., 2012). Systematic data noise was ruled out by visual inspection of waveforms and inversion of different data subsets (fig. 9 of Extended data). Random data noise is unlikely to produce a localised anomaly like the observed one, although its effect is difficult to quantify.

Other velocity anomalies The anomaly beneath Kolumbo is not the only strong negative anomaly present in the final model. At later iterations another LVZ of roughly similar size appears at $(20.0 ; 4.00$; $2.75) \mathrm{km}$. It is notably different from the Kolumbo anomaly which is introduced at the earliest, lowfrequency, stages of the inversion (fig. 7). Unlike the anomaly beneath Kolumbo, it reaches the surface cutting through a high-velocity block in the starting model (fig. 8). Its velocity is almost $1 \mathrm{~km} / \mathrm{s}$ greater than the LVZ under Kolumbo $(4.0-4.5 \mathrm{~km} / \mathrm{s}$ vs. $3.4 \mathrm{~km} / \mathrm{s})$. The estimated model error (fig. 9) was 0.08 $\mathrm{km} / \mathrm{s}$ at the Kolumbo anomaly and twice as much $(0.16 \mathrm{~km} / \mathrm{s})$ at the other LVZ. This suggests that these two features are of distinctly different nature and the latter may be spurious - a high-frequency overfitting artifact - potentially because the data constraining it were cycle-skipped and/or noisy (inset of fig. 5). 


\section{References}

Andinisari, R., Konstantinou, K., and Ranjan, P. (2021). Seismicity along the Santorini-Amorgos zone and its relationship with active tectonics and fluid distribution. Physics of the Earth and Planetary Interiors, 312:106660.

Annen, C., Blundy, J. D., and Sparks, R. S. (2006). The genesis of intermediate and silicic magmas in deep crustal hot zones. Journal of Petrology, 47(3):505-539.

Annen, C., Paulatto, M., Sparks, R. S. J., Minshull, T. A., and Kiddle, E. J. (2013). Quantification of the intrusive magma fluxes during magma chamber growth at Soufrière Hills volcano (Montserrat, Lesser Antilles). Journal of Petrology, 55(3):529-548.

Bachmann, O. and Bergantz, G. W. (2009). Rhyolites and their source mushes across tectonic settings. Journal of Petrology, 49(12):2277-2285.

Berryman, J. G. (1980). Long-wavelength propagation in composite elastic media II. Ellipsoidal inclusions. Journal of the Acoustical Society of America, 68:1820-1831.

Biot, M. (1956). Theory of elastic waves in a fluid-saturated porous solid. 1. Low frequency range. Journal of Acoustic Society of America, 28:168-178.

Boettcher, A. L. and Wyllie, P. J. (1968). Melting of granite with excess water to 30 kilobars pressure. Journal of Geology, 76(2):235- 244.

Bohnhoff, M., Rische, M., Meier, T., Becker, D., Stavrakakis, G., and Harjes, H.-P. (2006). Microseismic activity in the Hellenic volcanic arc, Greece, with emphasis on the seismotectonic setting of the Santorini-Amorgos zone. Tectonophysics, 423(1):17-33.

Bond, A. and Sparks, R. S. J. (1976). The Minoan eruption of Santorini, Greece. Journal of Geological Society of London, 132(1):1-16.

Booth, C. A., Kunz, B. E., and Jackson, M. D. (2019). Heat sources and the evolution of multiple magma reservoirs in the continental crust. In American Geophysical Union, Fall Meeting 2019, abstract \#V21A03.

Brown, S. K., Jenkins, S. F., Sparks, R. S. J., Odbert, H., and Auker, M. R. (2017). Volcanic fatalities database: analysis of volcanic threat with distance and victim classification. Journal of Applied Volcanology, 6(1):15.

Burgisser, A. and Bergantz, G. W. (2011). A rapid mechanism to remobilize and homogenize highly crystalline magma bodies. Nature, 471(7337):212-217.

Cadoux, A., Scaillet, B., Druitt, T. H., and Deloule, E. (2014). Magma storage conditions of large Plinian eruptions of Santorini volcano (Greece). Journal of Petrology, 55:1129-1171.

Calderón Agudo, O., Vieira da Silva, N., Warner, M., Kalinicheva, T., and Morgan, J. (2018). Addressing viscous effects in acoustic full-waveform inversion. Geophysics, 83:R611-R628.

Cantner, K., Carey, S., and Nomikou, P. (2014). Integrated volcanologic and petrologic analysis of the 1650AD erup-tion of Kolumbo submarine volcano, Greece. Journal of Volcanology and Geothermal Research, 269:28-43.

Carey, S., Nomikou, P., Bell, K. C., Lilley, M., Lupton, J., Roman, C., Stathopoulou, E., Bejelou, K., and Ballard, R. (2013). CO2 degassing from hydrothermal vents at Kolumbo submarine volcano, Greece, and the accumulation of acidic crater water. Geology, 41:1035-1038.

Caricchi, L., Townsend, M., Rivalta, E., and Namiki, A. (2021). The build-up and triggers of volcanic eruptions. Nature Reviews Earth \& Environment, 2(7):458-476.

Cashman, K. V., Sparks, R. S. J., and Blundy, J. D. (2017). Vertically extensive and unstable magmatic systems: A unified view of igneous processes. Science, 355. 
Cashman, K. V., Stephen, R., and Sparks, J. (2013). How volcanoes work: A 25 year perspective. Bulletin of the Geological Society of America, 125:664-690.

Cerjan, C., Kosloff, D., Kosloff, R., and Reshef, M. (1985). A nonreflecting boundary condition for discrete acoustic and elastic wave equations. Geophysics, 50(4):705-708.

Chrapkiewicz, K. (2021). High-resolution imaging beneath the Santorini volcano. PhD thesis, Imperial College London.

Christensen, N. I. (1979). Compressional wave velocities in rocks at high temperatures and pressures, critical thermal gradients, and crustal low-velocity zones. Journal of Geophysical Research, 84(B12):6849-6858.

Christensen, N. I. and Stanley, D. (2003). Seismic velocities and densities of rocks. International Geophysics, 81:1587-1594.

Cooper, K. M. and Kent, A. J. (2014). Rapid remobilization of magmatic crystals kept in cold storage. Nature, 506(7489):480-483.

Degruyter, W. and Huber, C. (2014). A model for eruption frequency of upper crustal silicic magma chambers. Earth and Planetary Science Letters, 403:117-130.

Dimitriadis, I., Karagianni, E., Panagiotopoulos, D., Papazachos, C., Hatzidimitriou, P., Bohnhoff, M., Rische, M., and Meier, T. (2009). Seismicity and active tectonics at Coloumbo Reef (Aegean Sea, Greece): Monitoring an active volcano at Santorini Volcanic Center using a temporary seismic network. Tectonophysics, 465:136-149.

Dimitriadis, I., Papazachos, C., Panagiotopoulos, D., Hatzidimitriou, P., Bohnhoff, M., Rische, M., and Meier, T. (2010). P and S velocity structures of the Santorini-Coloumbo volcanic system (Aegean Sea, Greece) obtained by non-linear inversion of travel times and its tectonic implications. Journal of Volcanology and Geothermal Research, 195:13-30.

Druitt, T. H., Costa, F., Deloule, E., Dungan, M., and Scaillet, B. (2012). Decadal to monthly timescales of magma transfer and reservoir growth at a caldera volcano. Nature, 482:77-80.

Dürig, T., White, J. D. L., Murch, A. P., Zimanowski, B., and others (2020). Deep-sea eruptions boosted by induced fuel-coolant explosions. Nature Geoscience.

England, P. C. and Katz, R. F. (2010). Melting above the anhydrous solidus controls the location of volcanic arcs. Nature, 467(7316):700-703.

Fuller, S., Carey, S., and Nomikou, P. (2018). Distribution of fine-grained tephra from the $1650 \mathrm{CE}$ submarine eruption of Kolumbo volcano, Greece. Journal of Volcanology and Geothermal Research, 352:10-25.

Gardner, G. H. F., Gardner, L. W., and Gregory, A. R. (1974). Formation velocity and density; the diagnostic basics for stratigraphic traps. Geophysics, 39.

Gassmann, F. (1951). Elastic waves through a packing of spheres. Geophysics, 16(4):673-685.

Gudmundsson, O., Brandsdottir, B., Menke, W., and Sigvaldason, G. E. (1994). The crustal magma chamber of the Katla volcano in south Iceland revealed by 2-D seismic undershooting. Geophysical Journal International, 119(1):277-296.

Hashin, Z. and Shtrikman, S. (1963). A variational approach to the theory of the elastic behaviour of multiphase materials. Journal of the Mechanics and Physics of Solids, 11:127-140.

Heath, B. A., Hooft, E. E., Toomey, D. R., Papazachos, C. B., Nomikou, P., Paulatto, M., Morgan, J. V., and Warner, M. R. (2019). Tectonism and Its Relation to Magmatism Around Santorini Volcano From Upper Crustal P Wave Velocity. Journal of Geophysical Research: Solid Earth, 124:10610-10629. 
Heath, B. A., Hooft, E. E. E., Toomey, D. R., and Bezada, M. J. (2015). Imaging the magmatic system of Newberry Volcano using Joint active source and teleseismic tomography. Geochemistry, Geophysics, Geosystems, 16:4433-4448.

Heah, B. A., Hooft, E. E. E., Toomey, D. R., Paulatto, M., Papazachos, C. B., Nomikou, P., and Morgan, J. V. (2021). Relationship between active faulting/fracturing and magmatism around santorini: Seismic anisotropy from an active source tomography experiment. Journal of Geophysical Research: Solid Earth, 126(8).

Holness, M. B., Stock, M. J., and Geist, D. (2019). Magma chambers versus mush zones: constraining the architecture of sub-volcanic plumbing systems from microstructural analysis of crystalline enclaves. Philosophical Transactions of the Royal Society A: Mathematical, Physical and Engineering Sciences, 377(2139):20180006.

Hooft, E. E., Nomikou, P., Toomey, D. R., Lampridou, D., Getz, C., Christopoulou, M.-E., O'Hara, D., Arnoux, G. M., Bodmer, M., Gray, M., Heath, B. A., and VanderBeek, B. P. (2017). Backarc tectonism, volcanism, and mass wasting shape seafloor morphology in the Santorini-Christiana-Amorgos region of the Hellenic Volcanic Arc. Tectonophysics, 712:396-414.

Hooft, E. E. E., Heath, B. A., Toomey, D. R., Paulatto, M., Papazachos, C. B., Nomikou, P., Morgan, J. V., and Warner, M. (2019). Seismic imaging of Santorini: Subsurface constraints on caldera collapse and present-day magma recharge. Earth and Planetary Science Letters, 514:48-61.

Huang, H.-H., Lin, F.-C., Schmandt, B., Farrell, J., Smith, R. B., and Tsai, V. C. (2015). The Yellowstone magmatic system from the mantle plume to the upper crust. Science.

Hübscher, C., Hensch, M., Dahm, T., Dehghani, A., Dimitriadis, I., Hort, M., and Taymaz, T. (2006). Toward a risk assessment of central Aegean volcanoes. Eos, 87.

Hübscher, C., Ruhnau, M., and Nomikou, P. (2015). Volcano-tectonic evolution of the polygenetic Kolumbo sub-marine volcano/Santorini (Aegean Sea). Journal of Volcanology and Geothermal Research, 291:101-111.

Jackson, M. D., Blundy, J., and Sparks, R. S. J. (2018). Chemical differentiation, cold storage and remobilization of magma in the Earth's crust. Nature.

Jellinek, A. M. and DePaolo, D. J. (2003). A model for the origin of large silicic magma chambers: precursors of caldera-forming eruptions. Bulletin of Volcanology, 65(5):363-381.

Kilias, S. P., Nomikou, P., Papanikolaou, D., Polymenakou, P. N., Godelitsas, A., Argyraki, A., Carey, S., Gamaletsos, P., Mertzimekis, T. J., Stathopoulou, E., Goettlicher, J., Steininger, R., Betzelou, K., Livanos, I., Christakis, C., Bell, K. C., and Scoullos, M. (2013). New insights into hydrothermal vent processes in the unique shallow-submarine arc-volcano, Kolumbo (Santorini), Greece. Scientific Reports, 3:1-13.

Kiser, E., Levander, A., Zelt, C., Schmandt, B., and Hansen, S. (2018). Focusing of melt near the top of the Mount St. Helens (USA) magma reservoir and its relationship to major volcanic eruptions. Geology, 46:775-778.

Klaver, M., Carey, S., Nomikou, P., Smet, I., Godelitsas, A., and Vroon, P. (2016). A distinct source and differentiation history for Kolumbo submarine volcano, Santorini volcanic field, Aegean arc. Geochemistry Geophysics Geosystems, 17:3254-3273.

Konstantinou, K. I. (2020). Magma chamber evolution during the 1650 AD Kolumbo eruption provides clues about past and future volcanic activity. Scientific Reports, 10:1-12.

Kusky, T. M. (2022). Déjà vu: Might future eruptions of Hunga Tonga-Hunga Ha'apai volcano be a repeat of the devastating eruption of Santorini, Greece (1650 BC)? Journal of Earth Science.

Lees, J. M. (2007). Seismic tomography of magmatic systems. Journal of Volcanology and Geothermal Research, 167:37-56. 
Lions, J. L. (1972). Nonhomogeneous boundary value problems and applications. Springer-Verlag, Berlin.

Magee, C., Stevenson, C. T. E., Ebmeier, S. K., Keir, D., Hammond, J. O. S., Gottsmann, J. H., Whaler, K. A., Schofield, N., Jackson, C. A.-L., Petronis, M. S., O’Driscoll, B., Morgan, J., Cruden, A., Vollgger, S. A., Dering, G., Micklethwaite, S., and Jackson, M. D. (2018). Magma Plumbing Systems: A Geophysical Perspective. Journal of Petrology, 59:1217- 1251.

Malcolm, A. E. and Trampert, J. (2011). Tomographic errors from wave front healing: more than just a fast bias. Geophysical Journal International, 185(1):385-402.

McVey, B. G., Hooft, E. E., Heath, B. A., Toomey, D. R., Paulatto, M., Morgan, J. V., Nomikou, P., and Papazachos, C. B. (2020). Magma accumulation beneath Santorini volcano from P-wave tomography. Geology, 48.

Morgan, J., Warner, M., Bell, R., Ashley, J., Barnes, D., Little, R., Roele, K., and Jones, C. (2013). Nextgeneration seis-mic experiments: Wide-angle, multi-azimuth, three-dimensional, full-waveform inversion. Geophysical Journal International, 195:1657-1678.

Mulder, W. A. and Plessix, R. E. (2008). Exploring some issues in acoustic full waveform inversion. Geophysical Prospecting, 56:827-841.

Nomikou, P., Carey, S., Bell, K. L. C., Papanikolaou, D., Bejelou, K., Cantner, K., Sakellariou, D., and Perros, I. (2014). Tsunami hazard risk of a future volcanic eruption of Kolumbo submarine volcano, NE of Santorini Caldera, Greece. Natural Hazards, 72:1375-1390.

Nomikou, P., Hübscher, C., Ruhnau, M., and Bejelou, K. (2016). Tectono-stratigraphic evolution through successive extensional events of the Anydros Basin, hosting Kolumbo volcanic field at the Aegean Sea, Greece. Tectonophysics, 671:202-217.

Nur, A., Mavko, G., Dvorkin, J., and Galmudi, D. (1998). Critical porosity: A key to relating physical properties to porosity in rocks. Leading Edge, 17(3):357-362.

Parks, M. M., Biggs, J., England, P., Mather, T. a., Nomikou, P., Palamartchouk, K., Papanikolaou, X., Paradissis, D., Parsons, B., Pyle, D. M., Raptakis, C., and Zacharis, V. (2012). Evolution of Santorini Volcano dominated by episodic and rapid fluxes of melt from depth. Nature Geoscience, 5:749-754.

Parmigiani, A., Degruyter, W., Leclaire, S., Huber, S., and Bachmann, O. (2017). The mechanics of shallow magma reservoir outgassing. Journal of Geophysical Research: Solid Earth.

Paulatto, M., Annen, C., Henstock, T. J., Kiddle, E., Minshull, T. A., Sparks, R. S. J., and Voight, B. (2012). Magma chamber properties from integrated seismic tomography and thermal modeling at Montserrat. Geochemistry, Geophysics, Geosystems, 13:1-18.

Paulatto, M., Moorkamp, M., Hautmann, S., Hooft, E., Morgan, J. V., and Sparks, R. S. J. (2019). Vertically Extensive Magma Reservoir Revealed From Joint Inversion and Quantitative Interpretation of Seismic and Gravity Data. Journal of Geophysical Research: Solid Earth, 124:11,170-11,191.

Peckover, R. S., Buchanan, D. J., and Ashby, D. (1973). Fuel-coolant interactions in submarine vulcanism. Nature, 245.

Popa, R.-G., Bachmann, O., and Huber, C. (2021). Explosive or effusive style of volcanic eruption determined by magma storage conditions. Nature Geoscience, 14(10):781-786.

Preine, J., Karstens, J., Hübscher, C., Nomikou, P., Schmid, F., Crutchley, G. J., Druitt, T. H., and Papanikolaou, D. (2021). Spatio-temporal evolution of the Christiana-Santorini-Kolumbo volcanic field, Aegean sea. Geology, 20.

Rawlinson, N., Fichtner, A., Sambridge, M., and Young, M. K. (2014). Seismic Tomography and the Assessment of Uncertainty. In Advances in Geophysics, volume 55, pages 1-76. Elsevier.

Rawlinson, N. and Spakman, W. (2016). On the use of sensitivity tests in seismic tomography. Geophysical Journal International, 205:1221-1243. 
Rizzo, A. L., Caracausi, A., Chavagnac, V., Nomikou, P., Polymenakou, P. N., Mandalakis, M., Kotoulas, G., Magoulas, A., Castillo, A., and Lampridou, D. (2016). Kolumbo submarine volcano (Greece): An active window into the Aegean subduction system. Scientific Reports, 6:1-9.

Rizzo, A. L., Caracausi, A., Chavagnac, V., Nomikou, P., Polymenakou, P. N., Mandalakis, M., Kotoulas, G., Magoulas, A., Castillo, A., Lampridou, D., Marusczak, N., and Sonke, J. E. (2019). Geochemistry of CO2-Rich gases venting from submarine volcanism: The case of Kolumbo (Hellenic Volcanic Arc, Greece). Frontiers of Earth Science, 7:60.

Rooyakkers, S. M., Stix, J., Berlo, K., Petrelli, M., and Sigmundsson, F. (2021). Eruption risks from covert silicic magma bodies. Geology, 49:1-5.

Schmid, F., Petersen, G., Hooft, E., Paulatto, M., Chrapkiewicz, K., Hensch, M., and Dahm, T. (2022). Heralds of a future eruption? Swarms of microseismicity below the submarine Kolumbo volcano indicate opening of near-vertical fracture zones that may be exploited by ascending melts. Geochemistry, Geophysics, Geosystems, in review. Preprint: https://doi.org/10.31223/X5B06S.

Seccia, D., Chiarabba, C., De Gori, P., Bianchi, I., and Hill, D. P. (2011). Evidence for the contemporary magmatic system beneath long valley caldera from local earthquake tomography and receiver function analysis. Journal of Geophysical Research: Solid Earth, 116(B12).

Seropian, G., Kennedy, B. M., Walter, T. R., Ichihara, M., and Jolly, A. D. (2021). A review framework of how earth-quakes trigger volcanic eruptions. Nature Communications, 12(1):1004.

Shah, N., Warner, M., Nangoo, T., Umpleby, A., Štekl, I., Morgan, J., and Guasch, L. (2012). Quality assured full-waveform inversion: Ensuring starting model adequacy. In SEG Technical Program Expanded Abstracts 2012, pages 1-5.

Sigurdsson, H., Carey, S., Alexandri, M., Vougioukalakis, G., Croff, K., Roman, C., Sakellariou, D., Anagnostou, C., Rousakis, G., loakim, C., Goguo, A., Ballas, D., Misaridis, T., and Nomikou, P. (2006). Marine investigations of Greece's Santorini Volcanic Field. Eos, 87(34):337.

Solano, J. M., Jackson, M. D., Sparks, R. S., Blundy, J. D., and Annen, C. (2012). Melt segregation in deep crustal hot zones: A mechanism for chemical differentiation, crustal assimilation and the formation of evolved magmas. Journal of Petrology, 53:1999-2026.

Sparks, R. S. J., Annen, C., Blundy, J. D., Cashman, K. V., Rust, A. C., and Jackson, M. D. (2019). Formation and dynamics of magma reservoirs. Philosophical Transactions of the Royal Society A: Mathematical, Physical and Engineering Sciences, 377:20180019.

Štekl, I., Umpleby, A., and Warner, M. (2010). Seismic anisotropy effects in 3D wavefield tomography. In 72nd EAGE Conference \& Exhibition, pages 1-5.

Takei, Y. (2002). Effect of pore geometry on Vp/Vs: From equilibrium geometry to crack. Journal of Geophysical Research, 107(B2).

Tarantola, A. (1984). Inversion of seismic reflection data in the acoustic approximation. Geophysics, 49:1259-1266.

Ueki, K. and Iwamori, H. (2016). Density and seismic velocity of hydrous melts under crustal and upper mantle conditions. Geochemistry Geophysics Geosystems, 17:1312-1338.

Ulvrova, M., Paris, R., Nomikou, P., Kelfoun, K., Leibrandt, S., Tappin, D. R., and McCoy, F. W. (2016). Source of the tsunami generated by the $1650 \mathrm{AD}$ eruption of Kolumbo submarine volcano (Aegean Sea, Greece). Journal of Volcanology and Geothermal Research, 321:125-139.

Virieux, J. and Operto, S. (2009). An overview of full-waveform inversion in exploration geophysics. Geophysics, 74:WCC1-WCC26.

Ward, K. M., Zandt, G., Beck, S. L., Christensen, D. H., and McFarlin, H. (2014). Seismic imaging of the magmatic underpinnings beneath the Altiplano-Puna volcanic complex from the joint inversion of surface wave dispersion and receiver functions. Earth and Planetary Science Letters, 404:43-53. 
Warner, M., Morgan, J., Umpleby, A., Štekl, I., and Guasch, L. (2012). Which physics for full-wavefield seismic inver-sion? In 74th EAGE Conference \& Exhibition, pages 1-5.

Warner, M., Ratcliffe, A., Nangoo, T., Morgan, J., Umpleby, A., Shah, N., Vinje, V., Štekl, I., Guasch, L., Win, C., Conroy, G., and Bertrand, A. (2013). Anisotropic 3D full-waveform inversion. Geophysics, 78:R59-R80.

Whittington, A. G., Hofmeister, A. M., and Nabelek, P. I. (2009). Temperature-dependent thermal diffusivity of the earth's crust and implications for magmatism. Nature, 458(7236):319-321.

Wohletz, K. \& Heiken, G. (1992) Volcanology and Geothermal Energy. Berkeley: University of California Press.

Zollo, A., Maercklin, N., Vassallo, M., Dello lacono, D., Virieux, J., and Gasparini, P. (2008). Seismic reflections reveal a massive melt layer feeding Campi Flegrei caldera. Geophysical Research Letters, 35:0-5. 